\title{
KARAKTERISTIK ANATOMI, FISIK MEKANIK, PENGERINGAN DAN KETERAWETAN KAYU KEMIRI (Aleurites moluccana Willd.)
}

\author{
The Characteristics of Anatomy, Physic, Mechanic, Drying and Treatability of Kemiri (Aleurites moluccana \\ Willd.) Wood \\ Muhammad Asdar dan Mody Lempang
}

\begin{abstract}
The aim of this research was to determine the anatomy, physical and mechanical properties, drying characteristics and treatability of kemiri wood. The observed paramaters were macroscophic and microscophic characteritics, moisture content, specific grafity, shrinkage, strength properties, drying quality, and the retention and penetration of wood preservative. Tests were run according to IAWA List, SNI and JIS. The heartwood colour is white to yellowish white and it is not clearly demarcated to the sapwood. Wood texture is rather coarse, stright grain, rather rough and rather glossy surface. The vessels are oval, diffuse porous, simple perforation plates. Parenchyma type is incomplete borders to the vessels and short tangential lines. Rays heterocellular are uniseriate and biseriate. Its fiber length is medium long size. Kemiri wood is classifed to strength class IV-III. Retention and penetration of wood preservative after 5 days in cold water treatment was met to SNI standard. The air drying test indicated the need of 8 days to achieve of the moisture content $12,29 \%$. Wood defects due to the air drying test can be occured in the forms of check, bowing, discolouration and blue stain.
\end{abstract}

Keywords: Wood anatomy, physical, mechanical, drying, treatability, Aleurites mollucana

\section{PENDAHULUAN}

Salah satu sentra kemiri nasional adalah Sulawesi Selatan dengan luas lahan mencapai 31.331 ha yang mampu memenuhi $44 \%$ kebutuhan kemiri nasional (Dinas Perkebunan Sulsel, 1992 dalam Yusran 2002). Penghasil kemiri terluas di Sulawesi Selatan adalah Kabupaten Maros yang mencapai 9.200 ha. Di daerah ini, terdapat indikasi penurunan produksi kemiri karena terdapat $79 \%$ pohon kemiri atau sekitar 216 pohon/ha yang sudah berumur tua (rata-rata berumur 45 tahun) dan tidak produktif lagi (Yusran, 2002). Jika dilakukan kegiatan permudaan, maka dapat dihasilkan minimal 2 juta $\mathrm{m}^{3}$ kayu dengan asumsi setiap pohon menghasilkan minimal $1 \mathrm{~m}^{3}$.

Kayu kemiri di Sulawesi Selatan umumnya digunakan untuk papan mal bangunan serta peti kemas dan sejak tahun 2004 mulai dimanfaatkan untuk pembuatan venir. Menurut Martawijaya, et al. (2005), kayu kemiri tergolong kelas kuat IV dan kelas awet IV - V. Kayu ini sangat mudah terserang jamur biru (blue stain) dan organisme perusak kayu lainnya. Meskipun demikian, kayu kemiri termasuk kayu yang mudah dikeringkan, diawetkan, dan mudah dalam pengerjaannya. Kayu ini dapat digunakan sebagai bahan venir inti, tusuk gigi, sumpit makan, peti, barang kerajinan (topeng dan wayang golek) dan mainan anak-anak.

Keawetan kayu kemiri yang rendah menuntut tindakan pencegahan terhadap serangan organisme perusak. Serangan jamur biru antara lain dapat dicegah dengan proses pengeringan yang segera untuk menurunkan kadar airnya, sedangkan terhadap organisme perusak lainnya diperlukan tindakan pengawetan kayu. Salah satu jenis bahan pengawet yang sering digunakan adalah campuran boraks dan asam borat karena relatif murah, larut air, dapat dilakukan dengan metode pengawetan sederhana serta tidak menimbulkan perubahan warna pada kayu. Menurut Hunt dan Garrat (1986), bahan pengawet ini dapat melindungi kayu dari serangan serangga dan cendawan serta untuk penghambat api. Kelemahannya adalah mudah tercuci sehingga tidak dapat digunakan pada kayu yang berhubungan dengan air atau tanah lembab.

Sifat kayu kemiri dari daerah ini belum banyak diketahui sehingga perlu diteliti mengingat potensinya yang besar. Hasil penelitian ini dapat menjadi pembanding dan pelengkap data sifat kayu kemiri yang telah diteliti dari daerah tempat tumbuh yang lain. 
Menurut Tsoumis (1968), pada spesies yang sama, sifat-sifat kayu dapat bervariasi disebabkan oleh dua faktor yaitu faktor lingkungan mikro (microenvironment) seperti perbedaan tempat tumbuh (perbedaan geografis dan ketinggian) dan faktor genetik (genetic constitution).

Penelitian ini bertujuan untuk mengetahui sifat-sifat kayu kemiri dari Sulawesi Selatan. Sifatsifat kayu yang diteliti meliputi karakteristik anatomi, sifat fisik dan mekanik, retensi dan penetrasi bahan pengawet serta mutu pengeringan kayu kemiri.

\section{METODE PENELITIAN}

\section{Metode Penelitian}

Kayu kemiri diambil dari Kab. Bantaeng Prop. Sulawesi Selatan. Sampel pohon sebanyak satu pohon berdiameter $47 \mathrm{~cm}$ dengan tinggi bebas cabang 5 meter. Sampel diambil pada posisi ketinggian 1,3 m (pangkal), 2,6 m (tengah) dan $4 \mathrm{~m}$ (ujung). Penelitian anatomi, fisik, keterawetan dan pengeringan dilaksanakan di Balai Litbang Kehutanan Sulawesi di Makassar, sedangkan sifat mekanik diuji di Fakultas Teknik Universitas Hasanuddin Makassar.

\section{Struktur Anatomi}

Sampel diambil dalam bentuk lempeng (disk) setebal $5 \mathrm{~cm}$ pada tiap-tiap posisi ketinggian. Contoh uji diambil pada bagian terluar (dekat kulit) pada arah yang berlawanan sebanyak 2 buah. Pembuatan preparat maserasi, mengikuti SNI 011840-1990 sedang preparat mikrotom mengikuti metode Sass (1958). Variabel yang diamati meliputi pori (diameter, frekuensi/mm, gabungan pori dan susunan pori), jari-jari (lebar, tinggi, frekuensi dan tipe jari-jari) dan dimensi serat (panjang, diameter serat, diameter lumen dan tebal dinding). Pengukuran lebar jari-jari, tebal dinding serat dan diameter pori menggunakan perbesaran $400 \mathrm{x}$, pengukuran panjang serat dan tinggi jari-jari menggunakan perbesaran $40 \times$ sedangkan pengukuran frekuensi pori dan jari-jari menggunakan perbesaran 100 x. Berdasarkan IAWA List (1989), jumlah serat, pembuluh dan jari-jari yang diukur sebanyak 25 buah, sedangkan frekuensi pori, gabungan pori dan frekuensi jari-jari 10 kali pengukuran. Penggolongan variabel anatomi secara kuantitatif berdasarkan Mandang dan Pandit (1997).

\section{Sifat Fisik dan Mekanik}

Contoh uji diambil secara acak sebanyak 15 buah pada tiap ketinggian dalam batang. Ukuran serta cara pengukuran dan pengujian contoh uji berat jenis nominal basah, kering udara dan kering tanur, kadar air basah dan kadar air kering udara, penyusutan pada arah radial dan tangensial dari basah ke kering udara dan dari basah ke kering tanur, keteguhan lentur statik, keteguhan pukul, keteguhan tekan sejajar serat dan keteguhan tekan tegak lurus serat berdasarkan standar JIS Z 2101, Z 2102, Z 2103, Z 2113, Z 2112 dan Z 2111 (Ginoga, 1974).

\section{Keterawetan Kayu}

Contoh uji berukuran $5 \times 5 \times 60 \mathrm{~cm}$ sebanyak 18 buah, masing-masing 6 buah tiap posisi ketinggian. Pengawetan kayu menggunakan metode rendaman dingin dengan lama perendaman 1, 3, dan 5 hari. Perbandingan antara boraks dan asam borat adalah $1: 1,54$ dan dilarutkan dalam air dengan konsentrasi $10 \%$. Uji retensi dan penetrasi diulang masing-masing sebanyak 3 kali (tiap-tiap posisi ketinggian diwakili oleh satu contoh uji).

Retensi dinyatakan dalam $\mathrm{kg} / \mathrm{m}^{3}$ yang ditetapkan dengan menimbang contoh uji sebelum dan sesudah pengawetan. Penetrasi diukur pada permukaan potongan melintang yang dibuat di bagian tengah contoh uji. Dalamnya penetrasi contoh uji dinyatakan dalam milimeter $(\mathrm{mm})$. Batas penembusan bahan pengawet diperjelas dengan melabur penampang contoh uji dengan pereaksi ekstrak kurkuma. Besarnya nilai retensi dan penetrasi bahan pengawet kayu dijadikan dasar penilaian keterawetan kayu berdasarkan standar SNI 033528-1994.

\section{Pengeringan Kayu}

Contoh uji berbentuk papan dibuat berdasarkan SNI 03-3527-1994 (lebar $15 \mathrm{~cm}$, tebal $2 \mathrm{~cm}$ dan panjang $100 \mathrm{~cm}$ ) sebanyak 15 lembar. Contoh uji tersebut diambil secara acak tanpa pertimbangan posisi dalam pohon. Pengeringan kayu dilakukan secara alami di atas lantai semen. Kayu disusun dengan model sandar pada udara terbuka dengan sisi tebal papan mengarah timur-barat. Kayu dikeringkan dalam kondisi segar hingga mencapai kadar air sekitar $15 \%$. Variabel yang diamati meliputi lama 
pengeringan, laju penurunan kadar air dan cacat pengeringan (retak, perubahan bentuk dan serangan jamur pewarna bila ada).

\section{Analisa Data}

Penelitian struktur anatomi, fisik dan mekanik menggunakan rancangan acak lengkap (RAL) dengan tiga perlakuan berdasarkan posisi ketinggian dalam batang yaitu pangkal batang $(A)$, tengah batang $(B)$ dan ujung batang $(C)$, sedangkan uji keterawetan menggunakan tiga perlakuan berdasarkan lama perendaman yaitu 1 hari (A), 3 hari $(B)$ dan 5 hari $(C)$. Data hasil pengukuran dan pengujian dianalisis dengan ANOVA dan uji lanjut dengan Uji Duncan. Pengolahan data menggunakan program komputer SPSS 11.0. Khusus pengeringan kayu, hasil pengamatan dihitung menggunakan nilai rata-rata dan persentase cacat kayu yang terjadi.

\section{HASIL DAN PEMBAHASAN}

\section{Karakteristik Anatomi}

Kayu kemiri yang diteliti memiliki karakteristik antara lain warna kayu putih kekuning-kuningan, tidak dapat dibedakan antara kayu gubal dan teras, tekstur agak kasar, arah serat lurus, kesan raba agak kesat, permukaan agak mengkilap, pori berbentuk lonjong dan tersebar tata baur, bidang perforasi sederhana, parenkim dua tipe yaitu paratrakeal selubung tidak lengkap dan apotrakeal berbentuk garis-garis tangensial pendek, serta jarijari heteroselular berseri satu sampai dua (uniseriat dan biseriat).
Hasil pengukuran dan pengamatan karakteristik anatomi kayu kemiri disajikan pada Tabel 1. Data menunjukkan bahwa diameter pori, diameter serat dan diameter lumen cenderung meningkat dari pangkal ke ujung batang. Lebar jari-jari dan frekuensi jari-jari meningkat pada bagian tengah kemudian turun pada bagian ujung, sedang tebal dinding turun dari pangkal ke ujung batang. Karakteristik lainnya memiliki pola cenderung menurun ke bagian tengah dan meningkat kembali ke ujung. Analisis ragam menunjukkan bahwa pada taraf $5 \%$, posisi batang berpengaruh nyata pada variabel diameter pori, lebar dan tinggi jari-jari serta sangat nyata pada diameter serat dan diameter lumen.

Uji lanjut Duncan menunjukkan bahwa diameter pori berbeda nyata pada bagian pangkal, tengah dan ujung. Lebar jari-jari pada bagian pangkal berbeda tidak nyata dengan ujung tetapi keduanya berbeda nyata dengan tengah. Tinggi jari-jari pada bagian tengah dan ujung berbeda tidak nyata tetapi keduanya berbeda nyata dengan pangkal. Diameter serat dan diameter lumen pada bagian pangkal berbeda tidak nyata dengan bagian tengah tetapi keduanya berbeda nyata dengan ujung.

Dibandingkan dengan Martawijaya et al. (2005), kayu yang diteliti memiliki diameter pori, frekuensi pori, lebar, tinggi dan frekuensi jari-jari yang relatif sama. Perbedaannya pada dimensi serat dan gabungan pori dimana kayu yang diteliti memiliki panjang serat yang lebih pendek dan tebal dinding yang lebih tipis, tetapi memiliki diameter serat dan lumen yang lebih besar serta pori soliter lebih sedikit.

Table 1. Anatomical characteristics of kemiri wood

\begin{tabular}{|l|l|c|c|c|c|c|}
\hline \multirow{2}{*}{ No. } & \multirow{2}{*}{ Anatomical characteristics } & \multicolumn{3}{|c|}{ Position in the trunk } & \multirow{2}{*}{ Avg. } & \multirow{2}{*}{ Remark } \\
\cline { 2 - 5 } & & Bottom & Middle & Top & & \\
\hline 1. & Vessel diameter $(\mu \mathrm{m})$ & $136.25 \mathrm{a}$ & $149.90 \mathrm{~b}$ & $179.20 \mathrm{c}$ & 155.12 & Agak kecil \\
2. & Vessel per sq. $\mathrm{mm}$ & 1.24 & 1.32 & 1.21 & 1.26 & Sangat jarang \\
3. & Vessel grouping $(\%)$ & 27.43 & 36.3 & 32.1 & 32.1 & Soliter dan \\
& & & & & & bergabung \\
4. & Rays height $(\mu \mathrm{m})$ & $518.00 \mathrm{c}$ & $436.20 \mathrm{a}$ & $474.00 \mathrm{ab}$ & 476.07 & Luar biasa pendek \\
5. & Rays depth $(\mu \mathrm{m})$ & $34.15 \mathrm{ab}$ & $37.88 \mathrm{c}$ & $32.70 \mathrm{a}$ & 34.91 & Agak sempit \\
6. & Rays per $\mathrm{mm}$ & 5.25 & 5.75 & 5.15 & 5.38 & Jarang \\
7. & Fiber length $(\mu \mathrm{m})$ & 1313 & 1391 & 1316 & 1340 & Sedang \\
8. & Fiber diameter $(\mu \mathrm{m})$ & $30.95 \mathrm{a}$ & $32.55 \mathrm{ab}$ & $35.15 \mathrm{c}$ & 32.88 & - \\
9. & Diameter of lumina $(\mu \mathrm{m})$ & $21.35 \mathrm{a}$ & $23.08 \mathrm{ab}$ & $26.15 \mathrm{c}$ & 23.79 & - \\
10 & Wall thickness $(\mu \mathrm{m})$ & 1.92 & 1.90 & 1.80 & 1.87 & - \\
\hline
\end{tabular}

Remarks: The value on the same row that followed by the same letter is not significantly different at $\alpha 0,05$ 


\section{Sifat Fisik}

Pengukuran sifat fisik kayu kemiri dilakukan pada kondisi segar, kering udara dan kering tanur. Nilai rata-rata hasil pengukuran sifat fisik disajikan pada Tabel 2.

Dari hasil pengukuran diketahui bahwa kayu kemiri dalam keadaan basah (segar) mengandung kadar air rata-rata 109,82 \% dan dalam keadaan kering udara rata-rata $10,28 \%$. Berat jenis nominal basah rata-rata 0,33 dan berat jenis kering udara rata-rata 0,39 serta berat jenis kering tanur rata-rata 0,38 . Berdasarkan klasifikasi kayu menurut Dumanauw (1982), maka kayu kemiri tergolong kayu ringan (berat jenis $<0,60$ ).

Berat jenis kering udara lebih tinggi dibanding pada kondisi kering tanur disebabkan perhitungan nilai berat jenis didasarkan pada berat dan volume pada masing-masing kondisi. Hasil pengukuran menunjukkan bahwa berat kayu dari kering udara ke kering tanur rata-rata turun $8,3 \%$ sedangkan volumenya hanya turun $5,5 \%$.
Kayu kemiri memiliki penyusutan sedang dengan penyusutan dari keadaan basah ke kering udara rata-rata 1,10\% (Radial) dan 2,47 $\%$ (Tangensial). Perbandingan penyusutan tangensial dan radial (T/R) kayu kemiri sebesar 2.25 menunjukkan bahwa kayu tersebut memiliki kestabilan dimensi yang cukup rendah. Panshin dan de Zeeuw (1980) mengemukakan bahwa nilai $T / R$ yang makin mendekati 1.00 berarti stabil. Keuntungan kayu kemiri adalah tidak terlalu banyak retak atau pecah pada saat pengeringan.

Hasil analisis ragam menunjukkan bahwa posisi ketinggian dalam batang hanya berpengaruh nyata terhadap penyusutan dari keadaan basah ke kering udara pada arah tangensial (T), sedangkan sifat fisik lainnya berpengaruh tidak nyata. Uji Duncan terhadap penyusutan tangensial dari basah ke kering udara menunjukkan bahwa posisi pangkal berbeda nyata dengan posisi tengah dan ujung, tetapi posisi tengah dan ujung berbeda tidak nyata.

Table 2. Physical properties of kemiri wood

\begin{tabular}{|c|c|c|c|c|c|c|}
\hline \multirow{2}{*}{ No. } & \multirow{2}{*}{ Physical properties } & \multirow{2}{*}{ Unit } & \multicolumn{3}{|c|}{ Position in the trunk } & \multirow{2}{*}{ Avg. } \\
\hline & & & Bottom & Middle & Top & \\
\hline 1. & Green moisture content & $\%$ & 114.30 & 109.17 & 106.01 & 109.82 \\
\hline 2. & Air dry moisture content & $\%$ & 10.38 & 10.34 & 10.11 & 10.28 \\
\hline 3. & Green specific grafity & - & 0.34 & 0.33 & 0.33 & 0.33 \\
\hline 4. & Air dry specific grafity & - & 0.40 & 0.39 & 0.39 & 0.39 \\
\hline 5. & Oven dry specific grafity & - & 0.38 & 0.38 & 0.37 & 0.38 \\
\hline 6. & Shrinkage green-air $d r$ & & & & & \\
\hline \multirow{4}{*}{7.} & Radial & $\%$ & 1.12 & 1.11 & 1.06 & 1.10 \\
\hline & Tangensial & $\%$ & $2.66 a$ & $2.31 b$ & $2.44 b c$ & 2.47 \\
\hline & $\begin{array}{l}\text { Shrinkage green-oven dry } \\
\text { Radial }\end{array}$ & $\%$ & 2.45 & 2.50 & 2.38 & 2.44 \\
\hline & Tangensial & $\%$ & 4.71 & 4.33 & 4.47 & 4.50 \\
\hline
\end{tabular}

Remarks: The value in the same row that followed by the same letter is not significantly different at $\alpha 0,05$

Table 3. Mechanical properties $\left(\mathrm{kg} / \mathrm{cm}^{2}\right)$

\begin{tabular}{|l|l|l|l|l|l|}
\hline \multirow{2}{*}{ No. } & \multicolumn{3}{|c|}{ Mechanical properties } & \multicolumn{3}{|c|}{ Position in the trunk } & \multirow{2}{*}{ Avg. } \\
\cline { 3 - 5 } & & \multicolumn{1}{|c|}{ Bottom } & \multicolumn{1}{|c|}{ Middle } & \\
\hline 1. & Static bending strength at proportional limit & 430.96 & 411.74 & 399.93 & 414.21 \\
2. & Ultimate bending strength & 555.12 & 530.47 & 518.31 & 534.63 \\
3. & Modulus of elasticity & $28399 \mathrm{a}$ & $12127 \mathrm{~b}$ & $13138 \mathrm{bc}$ & 17888 \\
4. & Compression parallel to the grain & 220.57 & 216.33 & 210.08 & 215.66 \\
5. & Copmression perpendicular to the grain & 54.65 & 46.16 & 43.42 & 48.08 \\
6. & Impact bending strength & 0.49 & 0.48 & 0.46 & 0.47 \\
\hline
\end{tabular}

Remarks: The value in the same row that followed by the same letter is not significantly different at $\alpha 0,05$ 
Dibandingkan dengan Martawijaya et al. (2005), sifat fisik kayu kemiri yang diteliti lebih baik misalnya berat jenis lebih tinggi dan penyusutan tangensial maupun radial yang lebih kecil.

\section{Sifat Mekanik}

Pengujian sifat mekanik kayu kemiri yang dilakukan pada kayu dalam kondisi kering udara diperoleh nilai rata-rata keteguhan lentur pada batas proporsi $414,21 \mathrm{~kg} / \mathrm{cm}^{2}$, keteguhan lentur pada batas patah $534,63 \mathrm{~kg} / \mathrm{cm}^{2}$ dan modulus elastisitasnya rata-rata $17.888 \mathrm{~kg} / \mathrm{cm}^{2}$, keteguhan tekan sejajar serat rata-rata $215,66 \mathrm{~kg} / \mathrm{cm}^{2}$, keteguhan tekan tegak lurus serat $48,08 \mathrm{~kg} / \mathrm{cm}^{2}$ dan keteguhan pukul rata-rata $0,47 \mathrm{~kg} / \mathrm{cm}^{2}$. Hasil pengujian selengkapnya disajikan pada Tabel 3 .

Di Indonesia, klasifikasi kekuatan kayu didasarkan pada keteguhan lentur pada batas patah dan keteguhan tekan sejajar serat. Berdasarkan nilai kedua sifat mekanik tersebut, maka kayu kemiri tergolong kelas kuat IV-III berdasarkan Den Berger (1923) dalam Martawijaya et al (2005).

Data pada Tabel 3 menunjukkan bahwa seperti halnya dengan sifat fisik, nilai rata-rata sifat mekanik juga cenderung menurun dari pangkal ke ujung batang. Hal ini dipengaruhi oleh kerapatan kayu yang juga menurun dari pangkal ke ujung batang. Semakin tinggi kerapatan kayu yang dicerminkan oleh berat jenis, maka semakin tinggi pula sifat mekaniknya. Analisis ragam menunjukkan bahwa posisi hanya berpengaruh sangat nyata pada nilai modulus elastisitas (MOE).

Hasil uji Duncan pengaruh posisi terhadap nilai MOE menunjukkan bahwa bagian pangkal berbeda nyata dengan bagian tengah dan ujung, sedangkan posisi tengah dan ujung berbeda tidak nyata. Nilai MOE bagian pangkal jauh lebih besar dibanding bagian tengah dan ujung. Hasil pengamatan selama pengujian menunjukkan bahwa bagian tengah dan ujung memiliki defleksi lebih tinggi $50 \%$ dibanding bagian pangkal. Nilai defleksi ini menjadi komponen pembagi dalam perhitungan MOE sehingga MOE tengah dan ujung menjadi jauh lebih rendah.

Dibandingkan dengan Martawijaya et al. (2005), maka kayu kemiri yang diteliti memiliki nilai keteguhan patah dan keteguhan tekan sejajar serat yang lebih baik, tetapi modulus elastisitas dan keteguhan pukulnya lebih rendah, sedangkan keteguhan tekan tegak lurus serat belum ada data.

\section{Keterawetan}

Pengawetan dengan perendaman dingin menghasilkan penetrasi rata-rata $18,68 \%$ atau $9,6 \mathrm{~mm}$ dan retensi rata-rata $18,85 \mathrm{~kg} / \mathrm{m}^{3}$.. Semakin lama perendaman, penetrasi dan retensi bahan pengawet semakin besar. Hasil analisis ragam menunjukkan bahwa lama perendaman berpengaruh nyata terhadap nilai penetrasi dan retensi.

Hasil uji Duncan menunjukkan bahwa perendaman selama 1 dan 3 hari menghasilkan penetrasi berbeda tidak nyata tetapi keduanya berbeda nyata dengan 5 hari. Sedangkan Uji Duncan retensi menunjukkan bahwa perendaman 3 dan 5 hari berbeda tidak nyata tetapi keduanya berbeda nyata dengan perendaman 1 hari. Uji Duncan selengkapnya pada Tabel 4.

Table 4. Duncan's Test of Penetration and Retention

\begin{tabular}{|c|c|c|}
\hline Days & Penetration & Retention \\
\hline 1 & $4,5967 \mathrm{a}$ & $9.06 \mathrm{a}$ \\
3 & $8,5133 \mathrm{ab}$ & $22,88 \mathrm{~b}$ \\
5 & $15,8167 \mathrm{c}$ & $24,60 \mathrm{bc}$ \\
\hline
\end{tabular}

Keterangan (Remarks):

Nilai-nilai dalam kolom yang sama yang diikuti oleh huruf yang sama berbeda tidak nyata pada a 0,05 (The value in the same column that followed by the same letter is not significantly different at $\alpha 0,05$ )

Berdasarkan standar SNI 03-3529-1994, maka perendaman selama 5 hari telah memenuhi syarat yaitu telah mencapai penetrasi lebih besar dari $10 \mathrm{~mm}$ dan retensi lebih besar dari $8 \mathrm{~kg} / \mathrm{m}^{3}$ untuk di bawah atap dan $11,4 \mathrm{~kg} / \mathrm{m}^{3}$ untuk di luar atap. Pengawetan kayu dengan menggunakan campuran boraks dan asam borat tidak merubah warna kayu kemiri.

\section{Pengeringan}

Kadar air awal (basah) papan sebelum dikeringkan adalah 114,73\%. Setelah pengeringan, rata-rata kadar air adalah 12,29\% (standar deviasi 1,4) yang diperoleh setelah dikeringkan selama 8 hari. Hal ini berarti bahwa laju pengeringan pada pengeringan alami mencapai 12,8\% kadar air per hari. Setelah dikeringkan secara alami, kayu berubah menjadi 
lebih gelap dari putih kekuningan menjadi coklat muda.

Cacat yang terjadi pada kayu akibat pengeringan antara lain retak-retak pada ujung papan $50 \%$, pecah $5 \%$, lengkung $65 \%$ dan blue stain $5 \%$. Persentasi kayu yang terserang blue stain relatif kecil karena kayu cepat dikeringkan dan suhu udara yang mencapai $36^{\circ} \mathrm{C}$ pada pukul 12.00 .

\section{KESIMPULAN DAN SARAN}

\section{Kesimpulan}

1. Warna kayu kemiri putih kekuningan, tidak jelas batas gubal dan teras, tekstur agak kasar, arah serat lurus, kesan raba agak kesat, permukaan agak mengkilap, pori berbentuk lonjong dan tersebar tata baur, bidang perforasi sederhana, parenkim tipe selubung tidak lengkap dan garisgaris tangensial pendek, jari-jari heteroselular, uniseriat dan biseriat. Pori tergolong agak kecil, frekuensi pori sangat jarang, pori soliter dan bergabung, jari-jari luar biasa pendek, sempit dan jarang. Panjang serat tergolong sedang.

2. Kadar air basah rata-rata $109,82 \%$, kadar air kering udara rata-rata $10,28 \%$. Berat jenis nominal basah rata-rata 0,33 , berat jenis kering udara rata-rata 0,39 dan berat jenis kering tanur rata-rata 0,38 . Nilai penyusutan radial dari basah ke kering udara rata-rata $1,10 \%$ dan dari basah ke kering tanur rata-rata $2,44 \%$. Nilai penyusutan tangensial dari basah ke kering udara rata-rata $2,47 \%$ dan dari basah ke kering tanur rata-rata $4,50 \%$.

3. Keteguhan lentur pada batas proporsi rata-rata $414,21 \mathrm{~kg} / \mathrm{cm}^{2}$, keteguhan lentur pada batas patah $534,63 \mathrm{~kg} / \mathrm{cm}^{2}$, modulus elastisitas 17.888 $\mathrm{kg} / \mathrm{cm}^{2}$, keteguhan tekan sejajar serat 215,66 $\mathrm{kg} / \mathrm{cm}^{2}$, keteguhan tekan tegak lurus serat 48,08 $\mathrm{kg} / \mathrm{cm}^{2}$ dan keteguhan pukul $0,47 \mathrm{~kg} / \mathrm{cm}^{2}$. Berdasarkan nilai berat jenis kering udara, keteguhan lentur pada batas patah dan keteguhan tekan sejajar serat, maka kemiri tergolong kayu kelas kuat IV-III.

4. Pengawetan rendaman dingin selama 5 hari telah memenuhi syarat penetrasi dan retensi dari SNI 03-3529-1994.

5. Pengeringan secara alami membutuhkan waktu 8 hari untuk mencapai KA 12,29. Cacat yang ditemui adalah retak ujung, pecah, lengkung dan bue stain.

\section{Saran}

1. Kayu kemiri dapat digunakan untuk komponen yang tidak mendapat beban berat pada tempat-tempat yang tidak bersentuhan dengan air atau kelembaban tinggi.

2. Untuk menghindari serangan blue stain, kayu yang baru ditebang harus segera dipotong dan dikeringkan.

\section{DAFTAR PUSTAKA}

Departemen Perindustrian. 1990. Cara uji panjang serat kayu dan bukan kayu. SNI 01-1840-1990.

Dewan Standardisasi Nasional 1994. Pengawetan kayu untuk rumah dan gedung. SNI 03-3528-1994

1994a. Mutu dan ukuran kayu bangunan. SNI 03-35271994.

Dumanauw, JF. 1982. Mengenal kayu. Gramedia. Jakarta

Ginoga, B. 1974. Pengujian sifat fisik dan mekanik kayu di Jepang. Publikasi Khusus No. 24. Lembaga Penelitian Hasil Hutan. Direktorat Jenderal Kehutanan Departemen Pertanian, Bogor.

Hunt, G.M dan G.A. Garrat. 1986. Pengawetan kayu. Terjemahan Muhammad Jusuf. Akademika Pressindo. Jakarta.

Mandang, Y.I. dan IKN. Pandit. 1997. Pedoman identifikasi jenis kayu di lapangan. Seri Manual. Yayasan Prosea dan Pusdiklat Pegawai dan SDM Kehutanan. Bogor.

Martawijaya, A., I. Karatsujana, K. Kadir dan S.A. Prawira. 2005. Atlas kayu Indonesia jilid II . Edisi Revisi. Badan Litbang Kehutanan. Dep. Kehutanan. Bogor.

Panshin, A.J. and C. de Zeeuw. 1980. Textbook of Wood Technology. McGraw-Hill Book Company. New York.

Sass, J. 1958. Botanical Microtechnique. $3^{\text {rd }}$. Ed. The lowa State University Press, Ames, Iowa, USA

Tsoumis, G. 1968. Wood as Raw Material. Source, Structure, Chemical Composition, Growth, Degradation and Identification. Pergamon Press Inc. 
Wheeler, E.A, P. Baas and P.E. Gasson (ed.). 1989. IAWA list of microscopic features for hardwood identification. IAWA Bulletin 10 (3) : 219-332. Leiden.

Yusran, 2002. Potensi dan prospek pengembangan hutan kemiri di Kabupaten Maros dalam menunjang otonomi daerah. Prosiding Dialog Kebijakan Hutan Kemasyarakatan "Mengembalikan Kejayaan Hutan Kemiri di Kabupaten Maros". Kerjasama Fak. Pertanian dan Kehutanan Unhas dan Ford Foundation. Maros, 18 April 2002.

Diterima : 01Juni 2006

Muh. Asdar dan Mody Lempong

Staf Peneliti Balai Penelitian dan Pengembangan Kehutanan Sulawesi

Jl. Perintis Kemerdekaan Km 17, Makassar 